\title{
Non-adaptive speciation of snails by left-right reversal is facilitated on oceanic islands
}

\author{
Masaki Hoso ${ }^{1,2}$ \\ ${ }^{1}$ Netherlands Centre for Biodiversity Naturalis, Leiden, P.O. Box 9517, 2300 RA Leiden, the Netherlands \\ ${ }^{2}$ E-mail:masakihoso@gmail.com
}

Key words: adaptive radiation, evolutionary novelty, innovation, island area, origin of species

\begin{abstract}
The nearly neutral theory of molecular evolution predicts that small population size is essential for non-adaptive evolution. Evolution of whole-body left-right reversal in snails is generally a compelling example of non-adaptive speciation, because variants with reversed chirality would suffer from reduced mating opportunities within a population. Despite this reproductive disadvantage, sinistral snail species have repeatedly originated from dextral ancestors in terrestrial pulmonates. Here I show that snail speciation by reversal has been accelerated on oceanic islands. Analysing the global biogeography of 995 genera across 84 stylommatophoran families, I found that the proportion of sinistral snail genera was enhanced in genera endemic to oceanic islands. Oceanic islands are relatively small land masses offering highly fragmented habitats for snails. Thus, the upper limit of population size would probably have been small for a long time there. Oceanic islands may have facilitated the fixation of the nonadaptive allele for speciation by reversal, allowing subsequent ecological divergence of sibling species. This study illustrates the potential role of genetic drift in non-adaptive speciation on oceanic islands.
\end{abstract}

\section{Contents}

Introduction

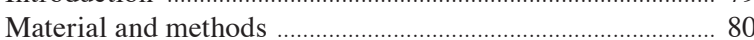

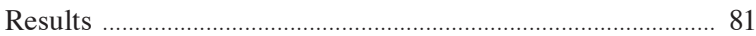

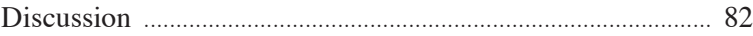

Acknowledgements ................................................................. 83

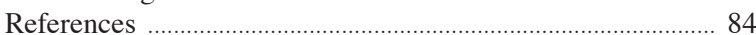

\section{Introduction}

Speciation occurs when populations accumulate genetic differences that cause reproductive incompatibility (Mayr, 1942). Genes for reproductive incompatibilities with other populations (speciation genes) could spread in a population by natural selection, sexual selection, genetic drift or a combination of these mechanisms (Coyne and Orr, 2004; Rundle and Nosil, 2005; Schluter, 2009; Presgraves, 2010; Nosil and Schluter, 2011; Servedio et al., 2011). However, the role of genetic drift has been thought to be small because the circumstances under which drift is a sole driver of speciation are considered to be limited (Marie Curie Speciation Network, 2012). When an allele of a speciation gene results in reduced fitness within the population (single-gene speciation; Orr, 1991), population fixation of this allele can only be driven by genetic drift. Alleles for coiling direction in snails may exemplify this.

Because of their helical shape, snails can be clearly classified by coiling phenotypes into either dextral (clockwise) or sinistral (counter-clockwise) morphs. Sinistral snail species originated multiple times in parallel from the vast majority of dextral snail lineages by right-left reversals, especially in terrestrial pulmonates (Vermeij, 1975; Schilthuizen and Davison, 2005). The cause for these evolutionary transitions in snail coiling direction has been an enigma to evolutionary biologists. Within those species that have been studied, reversal is determined by an allele at a single nuclear gene, with the phenotypic expression dependent on the maternal genotype (Degner, 1952; Murray and Clarke, 1976; Freeman and Lundelius, 1982; Utsuno and Asami, 2010). Because snails are reversed not only in coiling direction, but also in the position of the genital opening on the side of the body, dextral and sinistral snails may have difficulty copulating with each other (Gittenberger, 1988; Asami et al., 1998). The difficulties of mating with the majority coiling phenotype would result in lower fitness of the derived phenotype with reversed chirality (Johnson, 1982; Asami et al., 1998), maintaining populations monomorphic in coiling. If, however, the reversal does go to fixation in a population, premating isolation from other populations immediately becomes effective, giving rise to a new species (Gittenberger, 1988; Coyne and Orr, 2004).

Without either extraordinarily strong genetic drift (Orr, 1991; van Batenburg and Gittenberger, 1996) or natural selection for the reversal (Stone and Bjorklund, 
2002; Davison et al., 2005), snail speciation by reversal could only rarely occur. A recent study demonstrated origins of some sinistral snail species to be attributable to an adaptation against predation by snakes (Hoso et al., 2010). South-east Asian snakes in the family Pareatidae are dietary specialists on terrestrial snails and slugs (Cundall and Greene, 2000). Most of them are adapted for feeding on the dextral majority of snails by having right-asymmetric dentition (Hoso et al., 2007). Biogeographic analyses revealed that the distributions of sinistral snails were significantly associated with the presence of the snail-eating snakes (Hoso et al., 2010). Thus, if the presence of sinistral snail species within the snail-eating snakes' range is due to the presence of the predators, the question remains how sinistral snail species originate outside of the geographic range of the snakes.

Without considering snake predation, the allele for reversed coiling is reproductively disadvantageous when the reversed phenotype is still rare. Thus, small population size is a prerequisite for its fixation by genetic drift (Orr, 1991), as the nearly neutral theory of molecular evolution predicts (Ohta, 1973, 1992). However, for a new reverse-coiled species to evolve, the allele eventually needs to spread through all populations. Because of the delayed inheritance of the reversal, a dextral allele could be brought into the evolving population from neighbouring dextral populations. This inter-population gene flow inhibits completion of population fixation of reversal until the allele spreads into and then reaches fixation in all connectable populations (meta-population) not isolated by geological barriers (Orr, 1991; Davison et al., 2005).

Oceanic islands have provided terrestrial snails living there with relatively small habitats for long periods of time. They could be more conducive for snail speciation by reversal, since full fixation will take place more frequently and more quickly here. This hypothesis predicts that sinistral snail lineages more frequently emerge on oceanic islands. Furthermore, the effect of oceanic islands on the emergence of sinistral snail lineages should be greater in groups of tall-spired snails, because fixation of reversal solely by genetic drift is less likely in flat-spired snails than in tallspired snails (van Batenburg and Gittenberger, 1996) due to differences in copulation behaviour (Asami et al., 1998). Here, I test these predictions by analyses of the global distributions of dextral and sinistral stylommatophoran snail taxa, considering the deterministic effect of snake predation as well.

\section{Material and methods}

I classified all the recent terrestrial snail genera of the order Stylommatophora by size, shape, coiling direction and distribution according to information available in the literature in the same manner as in Hoso et al. (2010), with several additional references. I mostly followed the classification of Bouchet et al. (2005) augmented by other recent or more detailed references. All references where I collected data are listed in the On-line supplementary material (S1).

I excluded snail taxa unsuitable for the analyses, i.e., slugs with no or reduced shells, chirally dimorphic snail species in eleven genera and snails in the superfamily Clausilioidea, for the following reasons. Slugs and chirally dimorphic snails do not fit into the binary classification by coiling direction. The Clausilioidea is a cosmopolitan monophyletic taxon with a few exceptional dextral snail lineages, and is most likely to have descended from a single sinistral ancestor. I also excluded three genera with upturned apertures (Anostoma, Hendersoniella and Ringicella in Central and Southern America). After excluding these groups, I obtained data for 995 genera from 84 stylommatophoran families. The data matrix is available in On-line supplementary material (S2).

I treated a genus that include both dextral and sinistral snail species as two genera entirely composed of sinistral or dextral snail species. Hereafter I call a genus or a part of a genus that is entirely composed of sinistral snail species a sinistral snail genus.

Although genus-level phylogenies would allow better estimation of the number of reversals, they are unavailable. Instead, I used the number of sinistral snail genera, which would reflect the number of reversals from dextrality to sinistrality unless the number of sinistral snail genera has increased as a result of monophyletic radiation. To avoid the potential bias caused by amplified sinistral snail genera, I included the family to which each snail genus belongs as a random factor into generalized linear mixed models (GLMMs) for the following analyses. Because multiple families include sinistral snail genera regardless of shell shape, local distributions of particular snail taxa did not affect the present global-scale analyses. Although the number of reversals from sinistrality to dextrality in Clausilioidea and other potential cases may provide valuable insights as well, I did not use it because it cannot be properly counted and treated in the present statistical framework. 
I then classified snail genera as those endemic to oceanic islands and all others to distinguish the number of in situ speciation events by reversals on islands. I also classified snail genera as those partly or fully sympatric with pareatid snakes and all others. Because pareatid snakes do not inhabit oceanic islands, I assigned all snail genera to one of three categories: occurring on oceanic islands, occurring within the snake range or occurring neither on oceanic islands nor within the snake range. For the shell size of each genus, I used the shell diameter of the largest species in the genus. Shell diameter was log-transformed for the following parametric analysis.

Bimodal shell shapes are associated with discrete mating behaviours; tall-spired snails usually mate by shell mounting, and globular- to flat-spired snails mate face-to-face (Asami et al., 1998; Davison and Mordan, 2007) albeit with several exceptions (Jordaens et al., 2009a). Probably because interchiral mating is physically easier and thus selection is relaxed in species with shell-mounting copulation, sinistral snail genera have, in pulmonates, more frequently evolved in tallspired snail taxa, and populations are less likely to be fixed for the reversal solely by genetic drift in flatspired snails than in tall snails (Gittenberger, 1988; van Batenburg and Gittenberger, 1996; Asami et al., 1998). Thus, the effect of snake predation on the emergence of sinistral snail lineages is expected to be greater in genera of flat-spired snail species (Hoso et al., 2010).

Tall-spired snail genera were defined as having the shell height greater than the shell diameter, globular to flat-spired snail genera as having the height equal to or less than the diameter. This simple definition reflects the bimodality in the shell shape of terrestrial stylommatophoran pulmonates, as originally reported by Cain (1977) and subsequently by others (e.g., Cowie, 1995). Genera were assigned a binary code for shell shape: 378 genera fully composed of tall-shelled species (code 1) and 606 genera containing flat-spired snail species and 11 genera containing both tall and flat- spired snail species (code 0).

To test the effects of oceanic endemism and the oceanic-endemism $\times$ shell-shape interaction, I performed likelihood-ratio tests (LRTs) of a null model against a test model in accounting for the proportion of sinistral snail genera. Each of the focal effects was also incorporated as a fixed effect in the test model. I adopted pareatid snakes, shell size, shell shape, pareatid-snake $\times$ shell-size interaction and pareatid-snake $\times$ shell-shape interaction as covariates of these GLMMs.
In both tests, I did not include the other focal effect as a covariate because these two variables are strongly collinear.

To validate the mechanisms underlying the distribution pattern of sinistral snails, I performed AIC (Akaike Information Criterion)-based model selection among GLMMs in which all possible combinations of the fixed effects (oceanic endemism, pareatid snakes, shell size, shell shape and all pairwise interactions between them) were incorporated.

I conducted all analyses using $\mathrm{R}$ Version 2.14.0 ( $\mathrm{R}$ Development Core Team, 2011) with the lme4 package.

\section{Results}

I found 15 sinistral snail genera endemic to oceanic islands (Table 1). The effects of oceanic endemism and

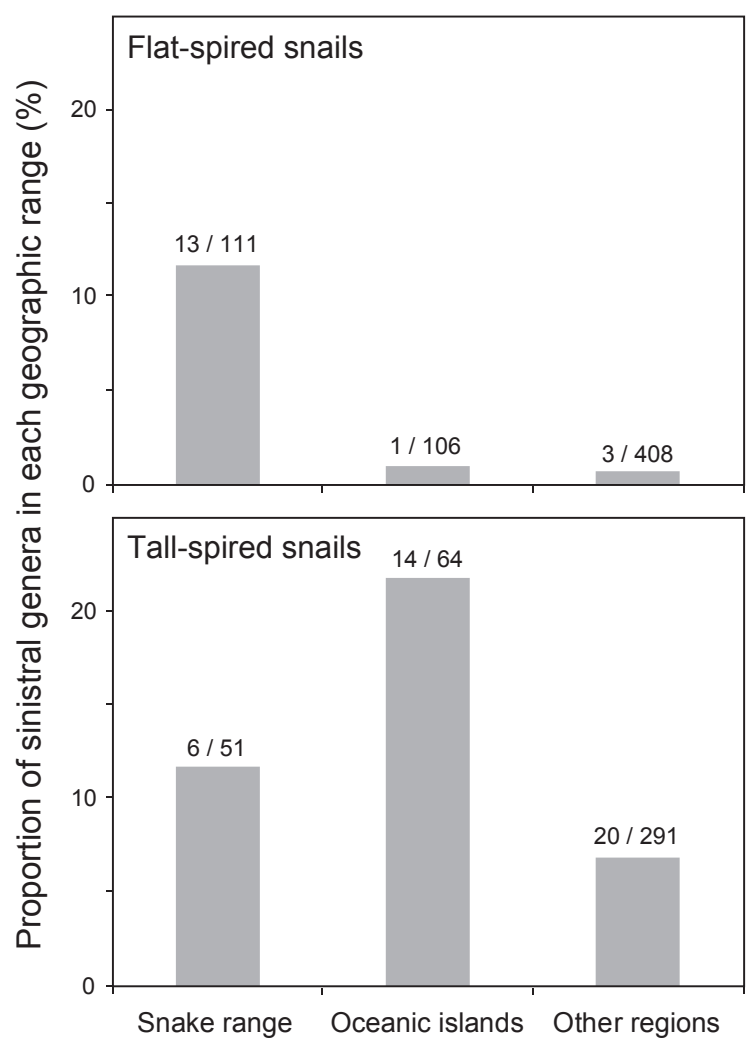

Fig. 1. Distribution pattern of sinistral terrestrial snails in association with oceanic islands and the geographic range of pareatid snail-eating snakes. Each bar indicates the proportion of genera composed of sinistral snail species. The numbers above each bar indicate the number of sinistral snail genera and the total number of genera included in each size range. 
Table 1. Sinistral snail genera endemic to oceanic islands.

\begin{tabular}{|c|c|c|c|c|}
\hline Family & Genus & Shell shape & Distribution of sinistral snails & Distribution of dextral snails \\
\hline \multirow[t]{5}{*}{ Achatinellidae } & Achatinella & tall & Hawaiian Islands & Hawaiian Islands \\
\hline & Auriculella & tall & Hawaiian Islands & Hawaiian Islands \\
\hline & Gulickia & tall & Hawaiian Islands & [none] \\
\hline & Newcombia & tall & Hawaiian Islands & [none] \\
\hline & Partulina & tall & Hawaiian Islands & Hawaiian Islands \\
\hline \multirow[t]{2}{*}{ Achatinidae } & Archachatina & tall & São Tome Island & African continent \\
\hline & Columna & tall & Principe Island & [none] \\
\hline \multirow[t]{3}{*}{ Amastridae } & Amastra & tall & Hawaiian Islands & Hawaiian Islands \\
\hline & Laminella & tall & Hawaiian Islands & Hawaiian Islands \\
\hline & Metamastra & tall & Hawaiian Islands & Hawaiian Islands \\
\hline \multirow[t]{2}{*}{ Partulidae } & Partula & tall & Belau to the Society Islands & Belau to the Society Islands \\
\hline & Samoana & tall & Polynesia and the Mariana Islands & Polynesia and the Mariana Islands \\
\hline Thyrophorellidae & Thyrophorella & flat & São Tome Island & [none] \\
\hline \multirow[t]{2}{*}{ Vertiginidae } & Lyropupa & tall & Hawaiian Islands & Hawaiian Islands \\
\hline & Nesopuparia & tall & Norfolk Islands & [none] \\
\hline
\end{tabular}

Table 2. Summaries of the generalized linear mixed model in accounting for the occurrence of sinistral snail genera.

Full model to test the effect of oceanic endemism (AIC: 378.3)

\begin{tabular}{lrl}
\hline & Estimate & SE \\
\hline (Intercept) & -5.089 & 0.808 \\
Oceanic endemism & 1.179 & 0.437 \\
Pareatid snakes & 0.829 & 1.482 \\
Shell shape & 2.516 & 0.650 \\
Shell size & -0.107 & 0.215 \\
Pareatid snakes $\times$ shell shape & -1.947 & 0.966 \\
Pareatid snakes $\times$ shell size & 0.677 & 0.415 \\
\hline
\end{tabular}

Table 3. Summary of the best generalized linear mixed model in accounting for the occurrence of sinistral snail genera (AIC: 373.9).

\begin{tabular}{lrl}
\hline & Estimate & SE \\
\hline (Intercept) & -4.601 & 0.693 \\
Shell shape & 2.412 & 0.586 \\
Shell size & -0.315 & 0.227 \\
Oceanic endemism $\times$ shell size & 0.590 & 0.189 \\
Pareatid snake $\times$ shell shape & -1.696 & 0.641 \\
Pareatid snake $\times$ shell size & 0.978 & 0.211 \\
\hline
\end{tabular}

the oceanic-endemism $\times$ shell-shape interaction were significant (Fig. 1; LRTs for comparing GLMMs, d.f. = 1 and $1, \chi^{2}=6.8$ and 7.0, $P=0.0093$ and $=0.0080$, respectively) on the proportion of sinistral snail genera. This result cannot be explained by a phylogenetic artifact because its effect was statistically removed. Also,
Full model to test the effect of oceanic-endemism $\times$ shell-shape interaction (AIC: 378)

\begin{tabular}{lrl}
\hline & Estimate & \multicolumn{1}{l}{ SE } \\
\hline (Intercept) & -4.731 & 0.795 \\
Oceanic endemism $\times$ shell shape & 1.292 & 0.462 \\
Pareatid snakes & 0.465 & 1.473 \\
Shell shape & 2.161 & 0.669 \\
Shell size & -0.119 & 0.213 \\
Pareatid snakes $\times$ shell shape & -1.588 & 0.972 \\
Pareatid snakes $\times$ shell size & 0.704 & 0.414 \\
\hline
\end{tabular}

it is probably robust for the same reason, although the number of genera is not definitive because generic limits, species composition and synonymies can change from time to time. The summaries of the GLMM analyses are shown in Table 2.

As a result of AIC-based model selection among GLMMs in accounting for the occurrence of sinistral snail genera, a model was selected in which shell shape, shell size, the oceanic-endemism $\times$ shell-size interaction, the pareatid-snakes $\times$ shell-size interaction and the pareatid-snakes $\times$ shell-shape interaction were incorporated as fixed effects. The summary of the GLMM analysis is shown in Table 3.

\section{Discussion}

I quantitatively documented the extraordinary diversity of sinistral snail lineages among snail taxa endemic to 
oceanic islands, as previously observed by Vermeij (1975). These sinistral snail lineages must have originated by left-right reversals from dextral ancestors on oceanic islands, unless their continental ancestors were already sinistral but are now extinct. Sinistral snail genera on oceanic islands and other regions lacking pareatid snakes are mostly tall-spired, in contrast to the situation within the snake range where sinistral snails mostly have flat shells. Tall-spired snails can perform interchiral mating relatively successfully because they copulate by shell-mounting (Johnson, 1982; Utsuno et al., 2010; but see Giokas et al., 2006), in contrast to flatspired snails that copulate face-to-face (Asami et al., 1998). The greater potential for interchiral mating would increase the likelihood of the population becoming fixed for the allele for reversed coiling. Thus, this distinctive pattern indicates that snail speciation by reversal has been accelerated by natural selection in the snake range and by genetic drift on oceanic islands.

Snail speciation by reversal could be also driven by divergent selection resulting from reproductive character displacement [RCD] (Uit de Weerd et al., 2006). RCD allows the snails to avoid disadvantageous copulation and hybridization with other related species with the same chirality, resulting in coexistence of related species pairs with the opposite chirality. However, some of the sinistral snail species on oceanic islands cannot provide evidence of $\mathrm{RCD}$, because they co-occur with no dextral congeners. Thus, RCD hypothesis may not be plausible for all the cases of snail speciation by reversal on oceanic islands, although the present global analysis does not exclude the potential effects of RCD.

Some groups of snail species on oceanic islands represent text-book examples of adaptive radiation (e.g., Schluter, 2000; Chiba, 2004; Parent and Crespi, 2009). The underling mechanisms for these radiations might have associations with the frequent speciation by reversal. However, left-right reversal in snails would not cause ecological divergence between the newly distinct species, without snake predation or RCD. Thus, species with reversed chirality would usually arise through non-adaptive speciation, which may precede ecological divergence of the newly distinct lineages, eventually leading to adaptive radiation (reviewed by Rundell and Price, 2009).

Most oceanic islands are characterized by volcanic disturbances and sharp topographical barriers. Such topology would offer fragmented habitats to terrestrial snails, separating snail populations and probably facilitating non-adaptive speciation (Cameron et al., 1996; Cook, 2008; Jordaens et al., 2009b). Moreover, because within-island speciation in terrestrial snails is common and only requires an extraordinarily small area (Kisel and Barraclough, 2010), oceanic islands are generally large enough to keep population sizes of snails smaller than those in continents. Thus, fragmented habitats rather than small island area might be responsible for the higher incidence of snail speciation by reversal on oceanic islands. However, it is not evident that volcanic regions of continents also harbour high diversity of sinistral snail species. And no oceanic island has been large since its birth. Clearly, further studies are needed to evaluate the effects of these two factors.

Sinistral snail genera are not evenly distributed across oceans. Of the 15 sinistral snail genera endemic to oceanic islands, 12 have a distribution in the Pacific and nine of them can be found only in Hawaiian Islands. Hawaiian sinistral snail species are assigned into three families and not monophyletic even among congeners (Holland and Hadfield, 2007), strongly suggesting repeated evolution of reversals there. The other three (out of 15) genera belong to two families and are endemic to São Tome and/or Principe Islands on the gulf of Guinea. In contrast to these evolutionary hotspots for chirality reversals, none or few reversals occurred on other oceanic islands including Azores, Galapagos and Bonin Islands which are well known regions for radiation of terrestrial snails. Although no valid hypotheses are currently available, exploring this contrast may provide us with meaningful insights in the accelerated snail speciation by reversal on oceanic islands.

Considering the effects of genetic drift on oceanic islands and selective predation by pareatid snakes in SE Asia, I illustrated why snail speciation by reversal has occurred so frequently. However, some aspects of the mechanism of speciation by reversal remain elusive. More fundamentally, the reason why the evolution of left-right reversal is largely confined to a few taxa (including gastropods) is still unanswered (see other papers in this special issue). Disentangling these challenging questions would allow for better understandings of the evolutionary mechanisms generating biodiversity and the origin of species.

\section{Acknowledgements}

I thank Y. Kameda and A.R. Palmer for providing information on sinistral snail taxa and the three reviewers (R.H. Cowie, G.J. Vermeij and E. Gittenberger) for helpful comments. This work was partly supported by a JSPS postdoctoral fellowship for research abroad. 


\section{References}

Asami T, Cowie RH, Ohbayashi K. 1998. Evolution of mirror images by sexually asymmetric mating behavior in hermaphroditic snails. American Naturalist 152: 225-236.

Batenburg FHD van, Gittenberger E. 1996. Ease of fixation of a change in coiling: computer experiments on chirality in snails. Heredity 76: 278-286.

Bouchet P, Rocroi JP, Fryda J, Hausdorf B, Ponder W, Valdes A, Waren A. 2005. Classification and nomenclator of gastropod families. Malacologia 47: 1-368.

Cain AJ. 1977. Variation in the spire index of some coiled gastropod shells, and its evolutionary significance. Philosophical Transactions of the Royal Society of London Series B-Biological Sciences 277: 377-428.

Cameron RAD, Cook LM, Hallows JD. 1996. Land snails on Porto Santo: adaptive and nonadaptive radiation. Philosophical Transactions of the Royal Society of London Series B-Biological Sciences 351: 309-327.

Chiba S. 2004. Ecological and morphological patterns in communities of land snails of the genus Mandarina from the Bonin Islands. Journal of Evolutionary Biology 17: 131-143.

Cook LM. 2008. Species richness in Madeiran land snails, and its causes. Journal of Biogeography 35: 647-653.

Cowie RH. 1995. Variation in species diversity and shell shape in Hawaiian land snails: In situ speciation and ecological relationships. Evolution 49: 1191-1202.

Cowie RH, Holland BS. 2008. Molecular biogeography and diversification of the endemic terrestrial fauna of the Hawaiian Islands. Philosophical Transactions of the Royal Society B-Biological Sciences 363: 3363-3376.

Coyne JA, Orr HA. 2004, Speciation. Sunderland, MA: Sinauer Associates.

Cundall D, Greene HW. 2000. Feeding in snakes. Pp. 293-333 in: Schwenk K, ed. Feeding: form, function, and evolution in tetrapod vertebrates. San Diego: Academic Press.

Davison A, Mordan P. 2007. A literature database on the mating behavior of stylommatophoran land snails and slugs. American Malacological Bulletin 23: 173-181.

Davison A, Chiba S, Barton NH, Clarke B. 2005. Speciation and gene flow between snails of opposite chirality. PLoS Biology 3: 1559-1571

Degner E. 1952. Der erbgang der inversion bei Laciniaria biplicata MTG. Mitteilungen der Hamburg Zoologisches Museum und Institut 51: 3-61.

Freeman G, Lundelius JW. 1982. The developmental genetics of dextrality and sinistrality in the gastropod Lymnaea peregra. Wilhelm Rouxs Archives of Developmental Biology 191: 69-83.

Gittenberger E. 1988. Sympatric speciation in snails - A largely neglected model. Evolution 42: 826-828.

Holland BS, Hadfield MG. 2007. Molecular systematics of the endangered O'ahu tree snail Achatinella mustelina: Synonymization of subspecies and estimation of gene flow between chiral morphs. Pacific Science 61: 53-66.

Hoso M, Asami T, Hori M. 2007. Right-handed snakes: convergent evolution of asymmetry for functional specialization. Biology Letters 3: 169-172.

Hoso M, Kameda Y, Wu SP, Asami T, Kato M, Hori M. 2010. A speciation gene for left-right reversal in snails results in anti-predator adaptation. Nature Communications 1: 133.
Johnson MS. 1982. Polymorphism for direction of coil in Partula suturalis - Behavioral isolation and positive frequencydependent selection. Heredity 49: 145-151.

Jordaens K, Dillen L, Backeljau T. 2009a. Shell shape and mating behaviour in pulmonate gastropods (Mollusca). Biological Journal of the Linnean Society 96: 306-321.

Jordaens K, Van Riel P, Martins AMF, Backeljau T. 2009b. Speciation on the Azores islands: congruent patterns in shell morphology, genital anatomy, and molecular markers in endemic land snails (Gastropoda, Leptaxinae). Biological Journal of the Linnean Society 97: 166-176.

Kisel Y, Barraclough TG. 2010. Speciation has a spatial scale that depends on levels of gene flow. American Naturalist 175: 316-334.

Marie Curie Speciation Network. 2012. What do we need to know about speciation? Trends in Ecology and Evolution 27: 27-39.

Mayr E. 1942, Systematics and the Origin of Species. New York: Columbia University Press.

Murray J, Clarke B. 1976. Supergenes in polymorphic land snails 2. Partula suturalis. Heredity 37: 271-282.

Nosil P, Schluter D. 2011. The genes underlying the process of speciation. Trends in Ecology and Evolution 26: 160-167.

Ohta T. 1973. Slightly deleterious mutant substitutions in evolution. Nature 246: 96-98.

Ohta T. 1992. The nearly neutral theory of molecular evolution. Annual Review of Ecology and Systematics 23: 263-286.

Orr HA. 1991. Is single-gene speciation possible? Evolution 45: 764-769.

Parent CE, Crespi BJ. 2009. Ecological opportunity in adaptive radiation of Galapagos endemic land snails. American Naturalist 174: 898-905.

Presgraves DC. 2010. The molecular evolutionary basis of species formation. Nature Reviews Genetics 11: 175-180.

R Development Core Team. 2011. R: A language and environment for statistical computing, Version 2.4.0. Vienna: $\mathrm{R}$ Foundation for Statistical Computing.

Rundell RJ, Price TD. 2009. Adaptive radiation, nonadaptive radiation, ecological speciation and nonecological speciation. Trends in Ecology and Evolution 24: 394-399.

Rundle HD, Nosil P. 2005. Ecological speciation. Ecology Letters 8: 336-352.

Schilthuizen M, Davison A. 2005. The convoluted evolution of snail chirality. Naturwissenschaften 92: 504-515.

Schluter D. 2000, Ecology of adaptive radiation. Oxford: Oxford University Press.

Schluter D. 2009. Evidence for ecological speciation and its alternative. Science 323: 737-741.

Servedio MR, Van Doorn GS, Kopp M, Frame AM, Nosil P. 2011. Magic traits in speciation: 'magic' but not rare? Trends in Ecology and Evolution 26: 389-397.

Stone J, Bjorklund M. 2002. Delayed prezygotic isolating mechanisms: evolution with a twist. Proceedings of the Royal Society of London Series B-Biological Sciences 269: 861-865.

Uit de Weerd DR, Groenenberg DSJ, Schilthuizen M, Gittenberger E. 2006. Reproductive character displacement by inversion of coiling in clausiliid snails (Gastropoda, Pulmonata). Biological Journal of the Linnean Society 88: $155-164$ 
Utsuno H, Asami T. 2010. Maternal inheritance of racemism in the terrestrial snail Bradybaena similaris. Journal of Heredity 101: 11-19.

Utsuno H, Kasem S, Fukuda H, Asami T. 2010. Genetic basis of racemism and ease of interchiral mating in a clausiliid species of snails. Molluscan Research 30: 37-47.

Vermeij GJ. 1975. Evolution and distribution of left-handed and planispiral coiling in snails. Nature 254: 419-420.

Received: 16 November 2011

Revised and accepted: 13 January 2012

Published online: 31 May 2012

Editor: M. Schilthuizen

\section{On-line supplementary material (SI)}

S1. References to the biogeographic data on snails and pareatid snakes. $S 2$. Data matrix of 995 genera from 84 stylommatophoran families. 
